\title{
硫黄化合物のガスクロマトグラフィーにおける試料直接導入法と プレカラム導入法の保持時間の関係
}

\author{
星加 安之, 小島一郎, 小池一美, 吉本 健二*
}

(1974 牦 9 月 20 日受理)

代表的な 33 種の硫黄化合物についてガスクロマトグラフィーを行い, 試料直接導入法と液体酸素温 度からのプレカラム導入法の相対保持時間（前者が $R_{\mathrm{tR}} \mathrm{d}$ ，後者が $R_{\mathrm{tR}} \mathrm{P}$ ，内標準硫化エチル），及びそ の比 $\left(R_{\mathrm{tR}} \mathrm{p} / R_{\mathrm{tR}} \mathrm{d}\right)$ を求为カラム充てえ剂の極性とカラム温度について検討した。充てえ剂はトリス一 2-シアノェトキシプロパン (強極性以下 TCEP と略記), リン酸トリクレジル（微極性以下 TCP と略 記)，ポリフェニルェーテル（微極性以下 PPE と略記）の 3 種を用いた。

その結果, $R_{\mathrm{tR}} / R_{\mathrm{tR}}$ の 範囲は TCEP が $0.7 \sim 1.7$, TCP が $0.7 \sim 2.0$, PPE が 0.5 2.2で TCEP が最も狭かった。一般的傾向としてての值は低沸点（低分子）のものほど大きく, 高沸点のものほど小 さかった。

カラム温度の影響は TCEP で硫化カルボニル, TCP で硫化水素の大きな減少のほかほほぼ定値 で影響はなかった。しかし，PPE は硫化水素を含む 13 種が大きく減少し中・高沸点化合物でも影響 があり， TCEP や TCP と比較してその差が明らかであった。本実験の結果，定性的には $R_{\mathrm{tR}}$ を $R_{\mathrm{tR}} \mathrm{d}$ から予測することが可能になった。

\section{1 緒言}

寒剂を用いた低温濃縮によるガスクロマトグラフ分析 法は, ppb から ppm レベルの大気中の硫黄化合物の分 析に有効な方法の一つである。なかでも，液体酸素トラ ップと FPD 付きガスクロマトグラフとの組み合わせ は，11 程度の濃縮で ppb から ppt レベルの極微量低 沸点硫黄化合物の分析が可能である1)2.

しかしプレカラム導入法では, 極低温から試料導入が 行われるため各分析対象物質の保持值が变化することか ら既存の直接導入法の保持值をそのま利用することは 問題である.

著者らは既に，数種の硫黄化合物と脂肪族アミン類に ついて, 直接導入法とプレカラム導入法の保持時間の間 には, ほぼ直線関係があり，直接導入法の保持值からプ レカラム導入法の保持值を推定することが可能なことを 報告した ${ }^{1)}$.

しかし，この関係が広い範囲の物質や充てん剂の極性 などの差異によっても成立するか否かは不明であった。

そこで，硫黄化合物のガスクロマトグラフィーにおけ る代表的な 33 種の物質を選び， $R_{\mathrm{tR}} \mathrm{d}, R_{\mathrm{tR}} \mathrm{P}, R_{\mathrm{tR}} \mathrm{p} /$

* 愛知県公害調查センター: 愛知県名古屋市北区辻町 流 7-6
$R_{\mathrm{tR}} \mathrm{d}$ を求め，この比がカラム充てん剂の極性やガスク ロマトグラフの操作条件などにどの程度影響されるが 知る目的で, 本実験を行った.

充て几剂は, 大気污染や悪臭分析に使用度の多い TCEP, TCP, PPE の 3 種. 検出器は FPD. ガスクロ

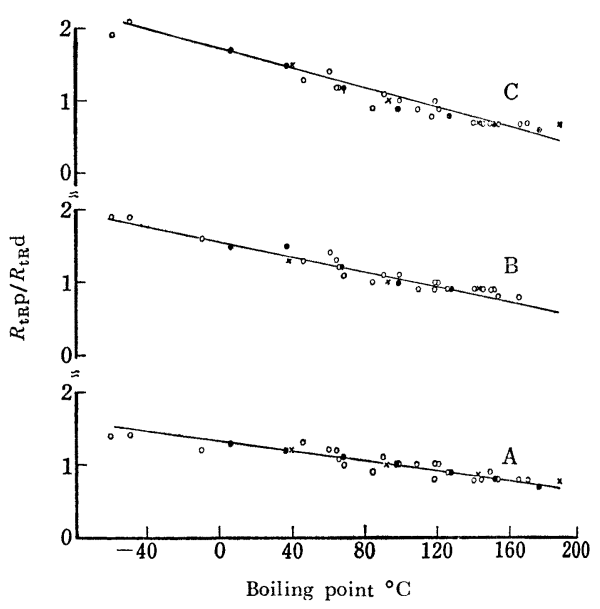

Fig. 1 Plot of $R_{\mathrm{tRP}} / R_{\mathrm{tR}} \mathrm{d} v s$. boiling point A : TCEP $75^{\circ} \mathrm{C} ; \quad$ B : TCP $75^{\circ} \mathrm{C} ; \quad \mathrm{C}:$ PPE $75^{\circ} \mathrm{C}$; - Represents $\mathrm{C}_{n} \mathrm{SH}$; $\times$ Represents $\mathrm{C}_{n} \mathrm{SC}_{n}$; O Represents others 
Table 1 Operating conditions of gas chromatography (Apparatus : Shimadzu GC 5AP $\mathrm{F}^{\mathrm{F}}$ )

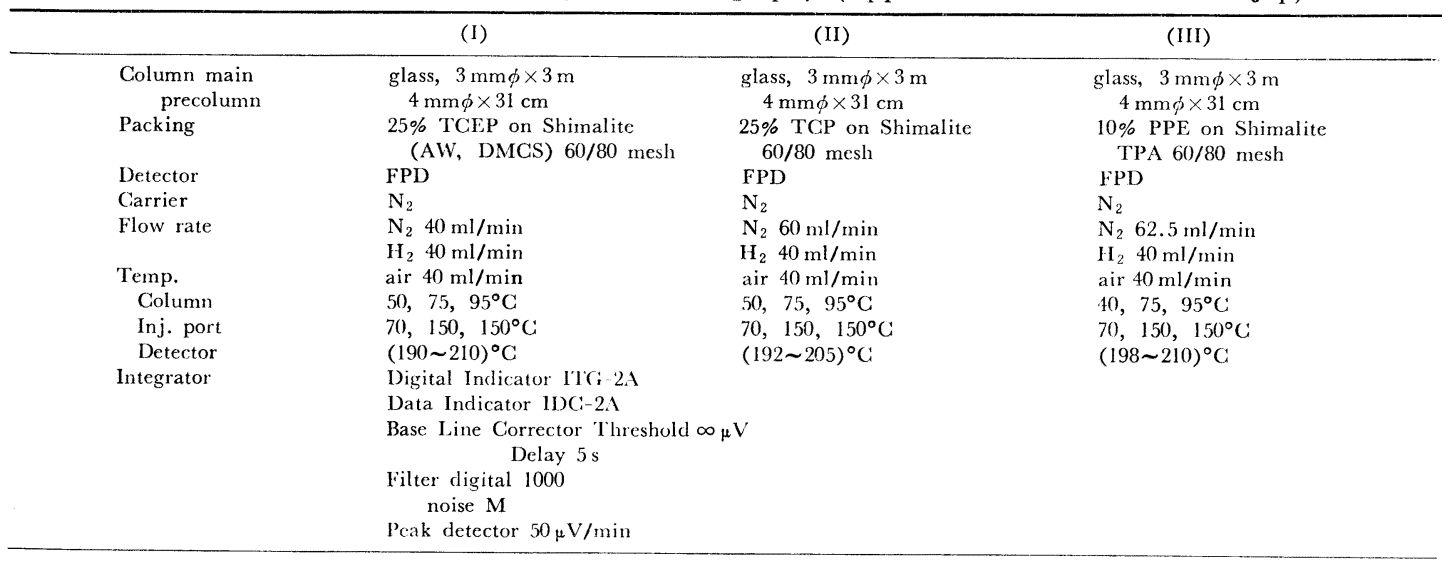

Table 2 Values of $R_{\mathrm{tR}} \mathrm{d}, R_{\mathrm{tR}} \mathrm{p}, R_{\mathrm{tR}} \mathrm{p} / R_{\mathrm{tR}} \mathrm{d}$ of sulfur compounds (in TCEP)

\begin{tabular}{|c|c|c|c|c|c|c|c|c|c|}
\hline & \multicolumn{8}{|c|}{ Temp. $\left({ }^{\circ} \mathrm{C}\right)$} & \multirow[b]{3}{*}{$R_{\mathrm{tRP}} / R_{\mathrm{tR}} \mathrm{d}$} \\
\hline & \multicolumn{3}{|c|}{50} & \multicolumn{3}{|c|}{75} & \multicolumn{2}{|r|}{95} & \\
\hline & $R_{\mathrm{tR}} \mathrm{d}$ & $R_{\mathrm{tnP}}$ & $R_{\mathrm{tR}} \mathrm{p} / R_{\mathrm{tR}} \mathrm{d}$ & $R_{\mathrm{tR}} \mathrm{d}$ & $R_{\mathrm{tR}} \mathrm{p}$ & $R_{\mathrm{tR}} \mathrm{p} / R_{\mathrm{tR}} \mathrm{d}$ & $R_{\mathrm{tR}} \mathrm{d}$ & $R_{\mathrm{tR}}$ & \\
\hline \multicolumn{10}{|l|}{ Mercaptans } \\
\hline $\mathrm{CH}_{3} \mathrm{SH}$ & 0.29 & 0.40 & 1.4 & 0.38 & 0.50 & 1.3 & 0.49 & 0.61 & 1.2 \\
\hline $\mathrm{C}_{2} \mathrm{H}_{5} \mathrm{SH}$ & 0.38 & 0.49 & 1.3 & 0.47 & 0.58 & 1.2 & 0.57 & 0.69 & 1.2 \\
\hline$n-\mathrm{C}_{3} \mathrm{H}_{7} \mathrm{SH}$ & 0.63 & 0.70 & 1.1 & 0.69 & 0.76 & 1.1 & 0.77 & 0.85 & 1.1 \\
\hline iso- $\mathrm{C}_{3} \mathrm{H}_{7} \mathrm{SH}$ & 0.40 & 0.51 & 1.3 & 0.49 & 0.59 & 1.2 & 0.57 & 0.67 & 1.2 \\
\hline $\mathrm{CH}_{2}=\mathrm{CHCH}_{2} \mathrm{SH}$ & 0.91 & 0.93 & 1.0 & 0.95 & 0.96 & 1.0 & 0.98 & 0.98 & 1.0 \\
\hline$n-\mathrm{C}_{4} \mathrm{H}_{9} \mathrm{SH}$ & 1.08 & 1.07 & 1.0 & 1.08 & 1.05 & 1.0 & 1.07 & 1.03 & 1.0 \\
\hline iso- $\mathrm{C}_{4} \mathrm{H}_{9} \mathrm{SH}$ & 0.78 & 0.83 & 1.1 & 0.84 & 0.86 & 1.0 & 0.87 & 0.91 & 1.1 \\
\hline sec- $\mathrm{C}_{4} \mathrm{H}_{9} \mathrm{SH}$ & 0.71 & 0.76 & 1.1 & 0.75 & 0.81 & 1.1 & 0.81 & 0.89 & 1.1 \\
\hline tert $-\mathrm{C}_{4} \mathrm{H}_{9} \mathrm{SH}$ & 0.38 & 0.48 & 1.3 & 0.47 & 0.58 & 1.2 & 0.53 & 0.67 & 1.3 \\
\hline$n-\mathrm{C}_{5} \mathrm{H}_{11} \mathrm{SH}$ & 1.85 & 1.70 & 0.9 & 1.72 & 1.51 & 0.9 & 1.56 & 1.35 & 0.9 \\
\hline sec, iso- $\mathrm{C}_{5} \mathrm{H}_{11} \mathrm{SH}$ & 1.07 & 1.08 & 1.0 & 1.10 & 1.04 & 1.0 & 1.08 & 1.03 & 1.0 \\
\hline tert $-\mathrm{C}_{5} \mathrm{H}_{11} \mathrm{SH}$ & 0.77 & 0.82 & 1.1 & 0.82 & 0.85 & 1.0 & 0.85 & 0.89 & 1.1 \\
\hline${ }_{n-}-\mathrm{C}_{6} \mathrm{H}_{13} \mathrm{SH}$ & 3.26 & 2.64 & 0.8 & 2.78 & 2.24 & 0.8 & 2.39 & 2.01 & 0.8 \\
\hline$n-\mathrm{C}_{7} \mathrm{H}_{15} \mathrm{SH}$ & 5.90 & 4.73 & 0.8 & 4.53 & 3.31 & 0.7 & 3.66 & 2.86 & 0.8 \\
\hline \multicolumn{10}{|l|}{ Sulfides } \\
\hline $\mathrm{H}_{2} \mathrm{~S}$ & 0.14 & 0.22 & 1.6 & 0.23 & 0.32 & 1.4 & 0.32 & 0.40 & 1.3 \\
\hline $\mathrm{CS}_{2}$ & 0.25 & 0.37 & 1.5 & 0.35 & 0.47 & 1.3 & 0.46 & 0.58 & 1.3 \\
\hline$\left(\mathrm{CH}_{3}\right)_{2} \mathrm{~S}$ & 0.45 & 0.55 & 1.2 & 0.54 & 0.64 & 1.2 & 0.64 & 0.74 & 1.2 \\
\hline $\mathrm{CH}_{3} \mathrm{SC}_{2} \mathrm{H}_{5}$ & 0.71 & 0.76 & 1.1 & 0.76 & 0.81 & 1.1 & 0.82 & 0.85 & 1.0 \\
\hline$\left(\mathrm{C}_{2} \mathrm{H}_{5}\right)_{2} \mathrm{~S}$ & 1.00 & 1.00 & 1.0 & 1.00 & 1.00 & 1.0 & 1.00 & 1.00 & 1.0 \\
\hline$\left(\mathrm{CH}_{2}=\mathrm{CHCH}_{2}\right)_{2} \mathrm{~S}$ & 4.75 & 3.92 & 0.8 & 3.92 & 2.97 & 0.8 & 3.32 & 2.62 & 0.8 \\
\hline$\left(n-\mathrm{C}_{3} \mathrm{H}_{7}\right)_{2} \mathrm{~S}$ & 2.44 & 2.17 & 0.9 & 2.09 & 1.78 & 0.9 & 1.86 & 1.55 & 0.8 \\
\hline$\left(\text { iso }-\mathrm{C}_{3} \mathrm{H}_{7}\right)_{2} \mathrm{~S}$ & 1.10 & 1.08 & 1.0 & 1.07 & 1.04 & 1.0 & 1.04 & 1.01 & 1.0 \\
\hline$n-\mathrm{C}_{4} \mathrm{H}_{9} \mathrm{SCH}_{3}$ & 1.85 & 1.70 & 0.9 & 1.76 & 1.60 & 0.9 & 1.58 & 1.38 & 0.9 \\
\hline$n-\mathrm{C}_{4} \mathrm{H}_{9} \mathrm{SC}_{2} \mathrm{H}_{5}$ & 2.78 & 2.35 & 0.8 & 2.31 & 1.93 & 0.8 & 1.99 & 1.64 & 0.8 \\
\hline$\left(n-\mathrm{C}_{4} \mathrm{H}_{9}\right)_{2} \mathrm{~S}$ & 7.22 & 5.70 & 0.8 & 5.30 & 4.07 & 0.8 & 4.18 & 3.09 & 0.7 \\
\hline$\left(\text { iso- } \mathrm{C}_{4} \mathrm{H}_{9}\right)_{2} \mathrm{~S}$ & 3.03 & 2.62 & 0.9 & 2.48 & 2.07 & 0.8 & 2.16 & 1.72 & 0.8 \\
\hline$\left(\sec -\mathrm{C}_{4} \mathrm{H}_{9}\right)_{2} \mathrm{~S}$ & 2.92 & 2.52 & 0.9 & 2.36 & 1.98 & 0.8 & 2.04 & 1.67 & 0.8 \\
\hline$\left(\text { tert }-\mathrm{C}_{4} \mathrm{H}_{9}\right)_{2} \mathrm{~S}$ & 1.74 & 1.73 & 1.0 & 1.62 & 1.44 & 0.9 & 1.44 & 1.28 & 0.9 \\
\hline \multicolumn{10}{|l|}{ Disulfides } \\
\hline$\left(\mathrm{CH}_{3}\right)_{2} \mathrm{~S}_{2}$ & 3.00 & 2.61 & 0.9 & 2.75 & 2.23 & 0.8 & 2.49 & 2.08 & 0.8 \\
\hline$\left(\mathrm{C}_{2} \mathrm{H}_{5}\right)_{2} \mathrm{~S}_{2}$ & 6.47 & 5.24 & 0.8 & 5.23 & 3.96 & 0.8 & 4.33 & 3.31 & 0.8 \\
\hline \multicolumn{10}{|l|}{ Miscellaneous } \\
\hline COS & 0.11 & 0.19 & 1.7 & 0.18 & 0.26 & 1.4 & 0.28 & 0.35 & 1.3 \\
\hline $\mathrm{SO}_{2}$ & 0.44 & 0.55 & 1.3 & 0.52 & 0.64 & 1.2 & 0.60 & 0.78 & 1.3 \\
\hline "s" & 2.16 & 1.97 & 0.9 & 2.05 & 1.74 & 0.9 & 1.87 & 1.55 & 0.8 \\
\hline \multirow[t]{2}{*}{ range } & & & 0.8 & & & 0.7 & & & 0.7 \\
\hline & & & $\sim 1.7$ & & & $\sim 1.5$ & & & $\sim 1.3$ \\
\hline
\end{tabular}


Table 3 Values of $R_{\mathrm{tR}} \mathrm{d}, R_{\mathrm{tR}} \mathrm{p}, R_{\mathrm{tR}} \mathrm{p} / R_{\mathrm{tR}} \mathrm{d}$ of sulfur compounds (in TCP)

\begin{tabular}{|c|c|c|c|c|c|c|c|c|c|}
\hline & \multicolumn{9}{|c|}{ Temp. $\left({ }^{\circ} \mathrm{C}\right)$} \\
\hline & \multicolumn{3}{|c|}{50} & \multicolumn{3}{|c|}{75} & \multicolumn{3}{|c|}{95} \\
\hline & $R_{\mathrm{tR}} \mathrm{d}$ & $R_{\mathrm{tR}} \mathrm{P}$ & $R_{\mathrm{tR}} \mathrm{P} / R_{\mathrm{tR}} \mathrm{d}$ & $R_{\mathrm{t} R} \mathrm{~d}$ & $R_{\mathrm{tR}} \mathrm{P}$ & $R_{\mathrm{tR}} \mathrm{P} / R_{\mathrm{tR}} \mathrm{d}$ & $R_{\mathrm{tR}} \mathrm{d}$ & $R_{\mathrm{tR}} \mathrm{P}$ & $R_{\mathrm{tR}} \mathrm{P} / R_{\mathrm{tR}} \mathrm{d}$ \\
\hline \multicolumn{10}{|l|}{ Mercaptans } \\
\hline $\mathrm{CH}_{3} \mathrm{SH}$ & 0.13 & 0.20 & 15 & 0.19 & 0.28 & 1.5 & 0.25 & 0.38 & 1.5 \\
\hline $\mathrm{C}_{2} \mathrm{H}_{5} \mathrm{SH}$ & 0.23 & 030 & 1.3 & 0.27 & 0.41 & 1.5 & 0.35 & 0.50 & 1.4 \\
\hline$n-\mathrm{C}_{3} \mathrm{H}_{7} \mathrm{SH}$ & 0.53 & 0.55 & 1.0 & 0.54 & 0.66 & 1.2 & 0.60 & 0.69 & 1.2 \\
\hline iso $-\mathrm{C}_{3} \mathrm{H}_{7} \mathrm{SH}$ & 0.31 & 0.37 & 1.2 & 0.35 & 0.48 & 1.4 & 0.42 & 0.55 & 1.3 \\
\hline $\mathrm{CH}_{2}=\mathrm{CHCH}_{2} \mathrm{SH}$ & 056 & 0.59 & 1.1 & 0.59 & 0.67 & 1.1 & 0.65 & 0.74 & 1.1 \\
\hline$n-\mathrm{C}_{4} \mathrm{H}_{9} \mathrm{SH}$ & 1.26 & 1.23 & 1.0 & 1.15 & 1.15 & 1.0 & 1.15 & 1.09 & 1.0 \\
\hline iso- $\mathrm{C}_{4} \mathrm{H}_{9} \mathrm{SH}$ & 0.87 & 0.85 & 1.0 & 0.82 & 0.88 & 1.1 & 0.87 & 0.89 & 1.0 \\
\hline sec $-\mathrm{C}_{4} \mathrm{H}_{9} \mathrm{SH}$ & 0.81 & 0.77 & 1.0 & 0.74 & 0.81 & 1.1 & 0.80 & 0.84 & 1.1 \\
\hline tert $-\mathrm{C}_{4} \mathrm{H}_{9} \mathrm{SH}$ & 0.40 & 0.41 & 1.0 & 0.39 & 0.51 & 1.3 & 0.46 & 0.59 & 1.3 \\
\hline$n-\mathrm{C}_{5} \mathrm{H}_{11} \mathrm{SH}$ & 2.79 & 2.52 & 09 & 2.46 & 2.17 & 0.9 & 2.23 & 1.84 & 0.8 \\
\hline sec, iso- $\mathrm{C}_{5} \mathrm{H}_{11} \mathrm{SH}$ & 1.45 & 1.46 & 1.0 & 1.40 & 1.32 & 0.9 & 1.37 & 1.25 & 0.9 \\
\hline tert $-\mathrm{C}_{5} \mathrm{H}_{11} \mathrm{SH}$ & 1.00 & 1.00 & 1.0 & 0.97 & 0.99 & 1.0 & 1.00 & 0.98 & 1.0 \\
\hline$n-\mathrm{C}_{6} \mathrm{H}_{13} \mathrm{SH}$ & - & - & - & 5.28 & 4.52 & 0.9 & 4.40 & 3.32 & 0.8 \\
\hline${ }^{n}-\mathrm{C}_{7} \mathrm{H}_{15} \mathrm{SH}$ & - & - & - & - & - & - & 8.74 & 6.44 & 0.7 \\
\hline \multicolumn{10}{|l|}{ Sulfides } \\
\hline $\mathrm{H}_{2} \mathrm{~S}$ & 0.05 & 0.10 & 2.0 & 0.09 & 0.17 & 1.9 & 0.15 & 0.24 & 1.6 \\
\hline $\mathrm{CS}_{2}$ & 0.27 & 0.34 & 1.3 & 0.36 & 0.45 & 1.3 & 0.43 & 0.58 & 1.4 \\
\hline$\left(\mathrm{CiH}_{3}\right)_{2} \mathrm{~S}$ & 0.25 & 0.33 & 1.3 & 0.32 & 0.43 & 1.3 & 0.39 & 0.52 & 1.3 \\
\hline $\mathrm{CH}_{3} \mathrm{SC}_{2} \mathrm{H}_{5}$ & 0.51 & 0.56 & 1.1 & 0.55 & 0.65 & 1.2 & 0.52 & 0.69 & 1.3 \\
\hline$\left(\mathrm{C}_{2} \mathrm{H}_{5}\right)_{2} \mathrm{~S}$ & 1.00 & 1.00 & 1.0 & 1.00 & 1.00 & 1.0 & 1.00 & 1.00 & 1.0 \\
\hline$\left(\mathrm{CH}_{2}=\mathrm{CHCH}_{2}\right)_{2} \mathrm{~S}$ & - & - & - & 4.00 & 3.44 & 0.9 & 3.53 & 2.78 & 0.8 \\
\hline$\left(n-\mathrm{C}_{3} \mathrm{H}_{7}\right)_{2} \mathrm{~S}$ & - & - & - & 3.77 & 3.20 & 0.9 & 3.26 & 2.57 & 0.8 \\
\hline$\left(\text { iso }-\mathrm{C}_{3} \mathrm{H}_{7}\right)_{2} \mathrm{~S}$ & 1.73 & 1.71 & 1.0 & 1.57 & 1.50 & 1.0 & 1.54 & 1.36 & 0.9 \\
\hline$n-\mathrm{C}_{4} \mathrm{H}_{9} \mathrm{SCH}_{3}$ & 2.58 & 2.44 & 1.0 & 2.28 & 1.97 & 0.9 & 2.08 & 1.77 & 0.9 \\
\hline$n-\mathrm{C}_{4} \mathrm{H}_{9} \mathrm{SC}_{2} \mathrm{H}_{5}$ & - & - & - & 3.95 & 3.42 & 0.9 & 3.36 & 2.68 & 0.8 \\
\hline$\left(n-\mathrm{C}_{4} \mathrm{H}_{7}\right)_{2} \mathrm{~S}$ & - & - & - & - & - & - & 12.00 & 8.70 & 0.7 \\
\hline (iso- $\left.\mathrm{C}_{4} \mathrm{H}_{9}\right)_{2} \mathrm{~S}$ & - & - & - & - & - & - & 5.52 & 4.18 & 0.8 \\
\hline$\left(\sec -\mathrm{C}_{4} \mathrm{H}_{3}\right)_{2} \mathrm{~S}$ & - & - & - & 6.48 & 5.37 & 0.8 & 5.28 & 4.02 & 0.8 \\
\hline$\left(\text { tert }-\mathrm{C}_{4} \mathrm{H}_{9}\right)_{2} \mathrm{~S}$ & - & - & - & 3.52 & 2.99 & 0.9 & 3.09 & 2.48 & 0.8 \\
\hline \multicolumn{10}{|l|}{ Disulfides } \\
\hline$\left(\mathrm{CH}_{3}\right)_{2} \mathrm{~S}_{2}$ & 2.34 & 2.31 & 1.0 & 2.15 & 1.97 & 0.9 & 2.07 & 1.78 & 0.9 \\
\hline$\left(\mathrm{C}_{2} \mathrm{H}_{3}\right)_{2} \mathrm{~S}_{2}$ & - & - & - & 7.30 & 6.02 & 0.8 & 6.03 & 4.60 & 0.8 \\
\hline \multicolumn{10}{|l|}{ Miscellaneous } \\
\hline $\cos$ & 0.05 & 0.09 & 1.8 & 0.09 & 0.17 & 1.9 & 0.14 & 0.25 & 1.8 \\
\hline $\mathrm{SO}_{2}$ & 0.14 & 0.23 & 1.6 & 0.20 & 0.31 & 1.6 & 0.24 & 0.43 & 1.8 \\
\hline$\|\mathrm{s}\|$ & 1.26 & 1.29 & 1.0 & 1.25 & 1.21 & 1.0 & 1.25 & 1.18 & 0.9 \\
\hline \multirow[t]{2}{*}{ range } & & & 0.9 & & & 0.8 & & & 0.7 \\
\hline & & & $\sim 2.0$ & & & $\sim 1.9$ & & & $\sim 1.8$ \\
\hline
\end{tabular}

マトグラフ操作条件はカラム温度を検討した.

\section{2 笑験}

\section{$2 \cdot 1$ 装置及び試薬}

本実験の装置及び試薬は既報 ${ }^{1)}$ のものとほぼ同様であ る。硫黄化合物は試薬を直接か，または $(1 〜 1300) \mathrm{ng} /$ $\mu \mathrm{l}$ 濃度のエタノール，n-ヘキサン，ベンゼン， $n$-ブタ, ールなどの溶液を用いた。二酸化硫黄は $1368 \mathrm{ppm}$ (窒 素ガスバランス）の標準ガス（製鉄化学製）を希釈して 用いた.

カラム充てん剂は和光純薬, 西尾工業製の市販品. そ の他の試薬はすべて特級品を用いた。 また，メインカラ ムとプレカラムには同一の充てえ剂を用いた。

\section{$2 \cdot 2$ 実験操作}

導入はいずれも直接法を最初に行い，プレカラム法を 後にした，直接法の場合もキャリヤーガス流路の不純物 除去管（モレキュラーシーブ $5 \mathrm{~A}, 6 \mathrm{~mm} \phi \times 40 \mathrm{~cm})^{1}$ ) 液体酸素に浸した状態で行い，プレカラム導入法の待ち 時間は 5 分間とし, 界温速度は $(-183 \sim+100)^{\circ} \mathrm{C} /$ 約 2.5 分に調節し，分析終了まで $100^{\circ} \mathrm{C}$ に保った. その 他のガスクロマトグラフ分析条件を Table 1 に示す.

\section{3 結果と考察}

\section{1 $\boldsymbol{R}_{\mathrm{tR}} \mathbf{d}, \boldsymbol{R}_{\mathrm{tR}} \mathbf{p}, \boldsymbol{R}_{\mathrm{tR}} \mathbf{p} / \boldsymbol{R}_{\mathrm{tR}} \mathbf{d}$ 值}

3.1.1 TCEP の場合 強極性の TCEP を用いた 場合のそれぞれの值を Table 2 に示す. 
Table 4 Values of $R_{\mathrm{tR}} \mathrm{d}, R_{\mathrm{tR}} \mathrm{p}, R_{\mathrm{tR}} \mathrm{p} / R_{\mathrm{tR}} \mathrm{d}$ of sulfur compounds (in PPE)

\begin{tabular}{|c|c|c|c|c|c|c|c|c|c|}
\hline & \multicolumn{8}{|c|}{ Temp. $\left({ }^{\circ} \mathrm{C}\right)$} & \\
\hline & \multirow[b]{2}{*}{$R_{\mathrm{tR}} \mathrm{d}$} & \multicolumn{3}{|l|}{40} & \multicolumn{2}{|l|}{75} & \multicolumn{3}{|c|}{95} \\
\hline & & $R_{\mathrm{tR}} \mathrm{p}$ & $R_{\mathrm{tR}} \mathrm{p} / R_{\mathrm{tR}} \mathrm{d}$ & $R_{\mathrm{t} \mathrm{R}} \mathrm{d}$ & $R_{\mathrm{tRP}}$ & $R_{\mathrm{tR}} \mathrm{p} / R_{\mathrm{tR}} \mathrm{d}$ & $R_{\mathrm{tR}} \mathrm{d}$ & $R_{\mathrm{tR}}$ & $R_{\mathrm{tR}} \mathrm{p} / R_{\mathrm{tR}} \mathrm{d}$ \\
\hline \multicolumn{10}{|l|}{ Mercaptans } \\
\hline $\mathrm{CH}_{3} \mathrm{SH}$ & 0.17 & 0.29 & 1.7 & 0.24 & 0.41 & 1.7 & 0.36 & 0.51 & 1.4 \\
\hline $\mathrm{C}_{2} \mathrm{H}_{5} \mathrm{SH}$ & 0.23 & 0.36 & 1.6 & 0.32 & 0.47 & 1.5 & 0.55 & 0.58 & 1.1 \\
\hline$n-\mathrm{C}_{3} \mathrm{H}_{7} \mathrm{SH}$ & 0.53 & 0.58 & 1.1 & 0.57 & 0.70 & 1.2 & 0.65 & 0.75 & 1.2 \\
\hline iso- $\mathrm{C}_{3} \mathrm{H}_{7} \mathrm{SH}$ & 0.30 & 0.41 & 1.4 & 0.39 & 0.54 & 1.4 & 0.50 & 0.64 & 1.3 \\
\hline $\mathrm{CH}_{2}=\mathrm{CHCH}_{2} \mathrm{SH}$ & 0.54 & 0.61 & 1.1 & 0.60 & 0.70 & 1.2 & 0.69 & 0.77 & 1.1 \\
\hline$n-\mathrm{C}_{4} \mathrm{H}_{9} \mathrm{SH}$ & 1.24 & 1.09 & 0.9 & 1.15 & 1.07 & 0.9 & 1.14 & 1.05 & 0.9 \\
\hline iso- $\mathrm{C}_{4} \mathrm{H}_{9} \mathrm{SH}$ & 0.83 & 0.82 & 1.0 & 0.85 & 0.88 & 1.0 & 0.90 & 0.89 & 1.0 \\
\hline sec $-\mathrm{C}_{4} \mathrm{H}_{9} \mathrm{SH}$ & 0.73 & 0.76 & 1.0 & 0.77 & 0.83 & 1.1 & 0.88 & 0.83 & 0.9 \\
\hline tert $-\mathrm{C}_{4} \mathrm{H}_{9} \mathrm{SH}$ & 0.35 & 0.46 & 1.3 & 0.47 & 0.58 & 1.2 & 0.57 & 0.66 & 1.2 \\
\hline$n-\mathrm{C}_{5} \mathrm{H}_{11} \mathrm{SH}$ & 2.78 & 2.32 & 0.8 & 2.41 & 1.84 & 0.8 & 2.21 & 1.57 & 0.7 \\
\hline sec, iso- $\mathrm{C}_{5} \mathrm{H}_{11} \mathrm{SH}$ & 1.43 & 1.32 & 0.9 & 1.38 & 1.22 & 0.9 & 1.37 & 1.18 & 0.9 \\
\hline tert $-\mathrm{C}_{5} \mathrm{H}_{11} \mathrm{SH}$ & 0.96 & 0.95 & 1.0 & 0.98 & 0.96 & 1.0 & 1.00 & 0.96 & 1.0 \\
\hline$n-\mathrm{C}_{6} \mathrm{H}_{13} \mathrm{SH}$ & 6.78 & 5.24 & 0.8 & 5.43 & 3.64 & 0.7 & 4.43 & 2.62 & 0.6 \\
\hline$n-\mathrm{C}_{7} \mathrm{H}_{15} \mathrm{SH}$ & - & - & - & 11.90 & 7.50 & 0.6 & 8.88 & 4.74 & 0.5 \\
\hline \multicolumn{10}{|l|}{ Sulfides } \\
\hline $\mathrm{H}_{2} \mathrm{~S}$ & 0.09 & 0.20 & 2.2 & 0.16 & 0.31 & 1.9 & 0.24 & 0.39 & 1.6 \\
\hline $\mathrm{CS}_{2}$ & 0.37 & 0.44 & 1.2 & 0.44 & 0.56 & 1.3 & 0.53 & 0.65 & 1.2 \\
\hline$\left(\mathrm{CH}_{3}\right)_{2} \mathrm{~S}$ & 0.27 & 0.38 & 1.4 & 0.35 & 0.53 & 1.5 & 0.47 & 0.63 & 1.3 \\
\hline $\mathrm{CH}_{3} \mathrm{SC}_{2} \mathrm{H}_{5}$ & 0.55 & 0.63 & 1.2 & 0.59 & 0.73 & 1.2 & 0.72 & 0.77 & 1.1 \\
\hline$\left(\mathrm{C}_{2} \mathrm{H}_{5}\right)_{2} \mathrm{~S}$ & 1.00 & 1.00 & 1.0 & 1.00 & 1.00 & 1.0 & 1.00 & 1.00 & 1.0 \\
\hline$\left(\mathrm{CH}_{2}=\mathrm{CHCH}_{2}\right)_{2} \mathrm{~S}$ & 5.00 & 3.85 & 0.8 & 4.07 & 3.00 & 0.7 & 3.60 & 2.26 & 0.6 \\
\hline$\left(n-\mathrm{C}_{3} \mathrm{H}_{7}\right)_{2} \mathrm{~S}$ & 4.93 & 3.67 & 0.7 & 3.84 & 2.86 & 0.7 & 3.09 & 2.13 & 0.7 \\
\hline$\left(\text { iso }-\mathrm{C}_{3} \mathrm{H}_{7}\right)_{2} \mathrm{~S}$ & 1.59 & 1.46 & 0.9 & 1.55 & 1.41 & 0.9 & 1.45 & 1.25 & 0.9 \\
\hline$n-\mathrm{C}_{4} \mathrm{H}_{9} \mathrm{SCH}_{3}$ & 2.38 & 2.20 & 0.9 & 2.30 & 1.90 & 0.8 & 2.01 & 1.55 & 0.8 \\
\hline$n-\mathrm{C}_{1} \mathrm{H}_{9} \mathrm{SC}_{2} \mathrm{H}_{5}$ & 4.43 & 3.90 & 0.9 & 3.97 & 2.95 & 0.7 & 3.20 & 2.16 & 0.7 \\
\hline$\left(n-\mathrm{C}_{4} \mathrm{H}_{9}\right)_{2} \mathrm{~S}$ & - & - & - & 17.00 & 11.10 & 0.7 & 11.60 & 6.18 & 0.5 \\
\hline$\left(\text { iso- }-\mathrm{C}_{4} \mathrm{H}_{3}\right)_{2} \mathrm{~S}$ & - & - & - & 7.23 & 5.06 & 0.7 & 5.37 & 3.24 & 0.6 \\
\hline$\left(\text { sec }-\mathrm{C}_{4} \mathrm{H}_{9}\right)_{2} \mathrm{~S}$ & 7.33 & 6.57 & 0.9 & 6.50 & 4.24 & 0.7 & 4.88 & 2.98 & 0.6 \\
\hline$\left(\text { terl }-\mathrm{C}_{4} \mathrm{H}_{9}\right)_{2} \mathrm{~S}$ & 3.92 & 3.39 & 0.9 & 3.49 & 2.53 & 0.7 & 2.91 & 1.99 & 0.7 \\
\hline \multicolumn{10}{|l|}{ Disulfides } \\
\hline$\left(\mathrm{CH}_{3}\right)_{2} \mathrm{~S}_{2}$ & 2.04 & 1.84 & 0.9 & 1.94 & 1.57 & 0.8 & 1.80 & 1.43 & 0.8 \\
\hline$\left(\mathrm{C}_{2} \mathrm{H}_{5}\right)_{2} \mathrm{~S}_{2}$ & 8.26 & 6.68 & 0.8 & 6.75 & 4.63 & 0.7 & 5.20 & 3.16 & 0.6 \\
\hline \multicolumn{10}{|l|}{ Miscellaneous } \\
\hline COS & 0.09 & 0.20 & 2.2 & 0.15 & 0.31 & 2.1 & 0.25 & 0.38 & 1.5 \\
\hline $\mathrm{SO}_{2}$ & 0.13 & 0.26 & 2.0 & 0.19 & 0.39 & 2.1 & 0.30 & 0.46 & 1.5 \\
\hline$\left\|{ }_{S}\right\|$ & 1.13 & 1.09 & 1.0 & 1.16 & 1.09 & 0.9 & 1.17 & 1.09 & 0.9 \\
\hline \multirow[t]{2}{*}{ range } & & & 0.7 & & & 0.6 & & & 0.5 \\
\hline & & & $\sim 2.2$ & & & $\sim 2.1$ & & & $\sim 1.6$ \\
\hline
\end{tabular}

$R_{\mathrm{tRp}} / R_{\mathrm{tR}} \mathrm{d}$ は $0.7 \sim 1.7$ で，低沸点（低分子）のも のほど大きく，高沸点のもの活ど小さい值を示したこ のことは後述の TCP，PPEに打いても悲められ，カラ ム充てえ剂の極性には関係なかった，各々の物質に刘す るカラム温度の影響は，硫化カルボニルの大きな減少の ほかは変化吕なく，中・高沸点化合物ではほ淁一定值を 示した.

3.1.2 TCP の場合微極性の TCP 学用いた場合 のそれぞれの值を Table 3 に示す.

$R_{\mathrm{tR}} / R_{\mathrm{tR}} \mathrm{d}$ は $0.7 \sim 2.0$ で, TCEP の場合よりも広 い範囲にわたった。

各々の物質に対するカラム温度の影響は，硫化水素の 大きな減少のほかはほぼ一定值を示した。
3.1.3 PPE の場合微極性のPPE 䒚相いた場合 のそれ弪れの值を Table 4 に亦歺.

$R_{\mathrm{tRP}} / R_{\mathrm{tR}}$ は $0.5 \sim 2.2$ で，TCEP，TCP の埸合に 比べて最も範罒が広かった。

各々の物質に対するカラム温度の影響は，大きな減少 を示与ものが硫化水素を含导 13 種で，川1・高沸点化合 物でも影響があり TCEP，TCPとの㾏が頙著であった。

\section{2 $\boldsymbol{R}_{\mathrm{tR}} \mathbf{p} / \boldsymbol{R}_{\mathrm{tR}} \mathbf{d}$ 值と沸点及び炭素数の関係}

直鎖メルカプタン，サルフォイドなどの同族列間に少 いては 3 種のカラムとも， $R_{\mathrm{tR}} \mathrm{p} / R_{\mathrm{tR}} \mathrm{d}$ 值と沸点（又は 炭素数）のプロットはぼほ直線関係になった。

$75^{\circ} \mathrm{C}$ の場合を Fig. 1, Fig. 2 に示す. 


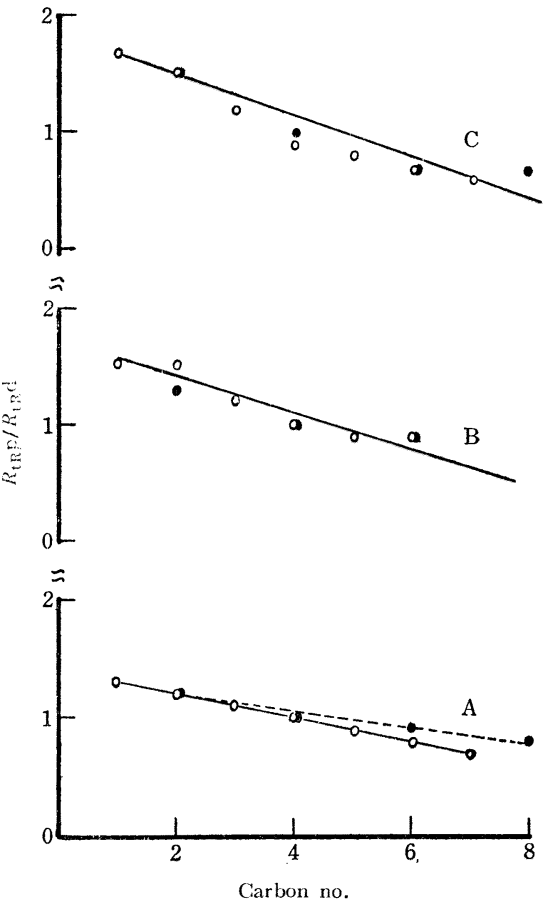

Fig. 2 Plot of $R_{\mathrm{tR}} \mathrm{P} / R_{\mathrm{tR}} \mathrm{d} v s$. carbon no.

A : TCLP $75^{\circ} \mathrm{C}$; B : TCP $75^{\circ} \mathrm{C}$; PPL : $75^{\circ} \mathrm{C}$; O Represents $\mathrm{C}_{n} \mathrm{SH}$; Represcnts $\mathrm{C}_{n} \mathrm{SC}_{n}$

$$
4 \text { 結 } \overline{\overline{1}}
$$

本”实験の結果から次のことが明らふに㾂のた。

（1）分離の点からは直接導入法もプレカラム導入法 も重複するピークの数は变わらない, 徒って実際の分析 に当たってもプレカラム導入法での分離の向上は期待で きない。

（2）プレカラム眿入法で実際の分析を行う場合は， あらかじめ標準物質について測定した $R_{\mathrm{tR}} \mathrm{p}$ 值を碑いて 物質の同定を行うことができる.

(3) 本実験で得られたデータふらは， $R_{\mathrm{tR}} \mathrm{p}$ を $R_{\mathrm{tR}} \mathrm{d}$ から宝性的に予測できるが末知化合物についての正確な 推缹は若干問题である。

終わりに，本実験を定施するに当たり終始御指導を賜

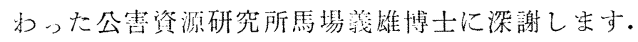

\section{交献}

1）星加安之，角脇 椧，小囟一郎，小池一美，吉本 健二：本誌，23，917 (1974).

2）星加安之，小島一郎，小池一美，吉本健二：同 上, 23, 1393 (1974).

$$
\text { 㝋 }
$$

Relationship between retention time of direct injection method and retention time of precolumn injection method of the sulfur compounds in gas chromatography. Yasuyuki Hoshik A, Ichiro Kozima, Kazumi Korke and Kenji Yoshimoto (Aichi Environmental Research Center, 7-6, Nagare, Tsujimachi, Kita-ku, Nagoya-shi, Aichi)

For the purpose of establishing a conclusive identification method on gas chromatographic analyses of a trace amount of the sulfur compounds in an ambient air, the relative retention times of 33 typical sulfur compounds were measured, as internal standard, diethyl sulfide. The measurements were achieved to compare with the relative retention time of direct injection method into main column $(3 \mathrm{~mm}$ i. d. $3 \mathrm{~m}$ long, phosphoric acid treated glass column $)\left(R_{\mathrm{tR}} \mathrm{d}\right)$ and that of precolumn injection method throughout cooling precolumn ( $4 \mathrm{~mm} \mathrm{i.d.} 31 \mathrm{~cm}$ long, phosphoric acid treated glass column) ( $\left.R_{\mathrm{tR}} \mathrm{p}\right)$ in liquid oxygen. The polarity of the liquid phase of column packings and column temperatures were also examined.

The ratio of relative retention time, $R_{\mathrm{tR}} / R_{\mathrm{tR}} \mathrm{d}$ values of 33 sulfur compounds were $0.7 \sim 1.7$ in tris (2-cyanoethoxy) propane (TCEP, strong polarity), $0.7 \sim 2.0$ in tricresylphosphate (TCP, poor polarity), $0.5 \sim 2.2$ in polyphenylether (PPE, poor polarity), respectively.

In general, the $R_{\mathrm{tR}} \mathrm{P} / R_{\mathrm{tR}} \mathrm{d}$ values of sulfur compounds even if no effect with increasing of column temperature, but several exceptions were observed, i.e., carbonyl suliide in TCEP, hydrogen sulfide in TCP, 13 compounds including hydrogen sulfide in PPE.

In conclusion, the estimation of $R_{\mathrm{tR}} \mathrm{p}$ values from the $R_{\mathrm{t} R}$ d values are possible qualitatively.

(Received Sept. 20, 1974)

\section{Keywords}

Direct and precolumn

Gas chromatography

Retention time

Sulfur compounds 